\title{
Management Communication with impact!
}

"To be effective in business, you have to communicate well. To be a good manager, you have to communicate exceptionally well". This was the opening of a newsletter sent to all people managers in Danfoss on October 13, 2010 from Chief Reputation Officer Ole Daugbjerg. Attached was a booklet titled 'Management Communication Tool Kit'.

\section{Management Communication Tool Kit}

The newsletter was an important milestone for the internal communication community in Danfoss. With the launch of the new Danfoss strategy 'Core \& Clear' in January 2010, Danfoss' internal communication faced one of the biggest communication tasks in its history. The Management Communication Tool Kit was the outcome of a concerted effort between the HR community and the internal communication community to ensure a professional communication of the new strategy.

So what is professional communication? Well, when looking into theory and research there is an endless number of answers to this question. However, when developing the tool kit, particular attention was paid to the following conclusions:

1. The most important communication channel is the immediate manager (see for example Larkin \& Larkin, "Communicating big change", 2006).

2. Communication needs to be tailored according to the target group (see for example David Grosman, You Can't Not Communicate: Proven Communication Solutions That Power The Fortune 100, AuthorHouse 2009)

3. Face-to-face communication is the employee's preferred communication channel (see for example Rogen International, New York 2001).

These three findings made it very clear that the greatest results would be reached by supporting middle management in solving the communication task. This became the outset for the development of the Tool Kit.

\section{The 7 Elements of Communication}

The Tool Kit is a 15-page booklet based on the so-called '7 Elements of Communication':

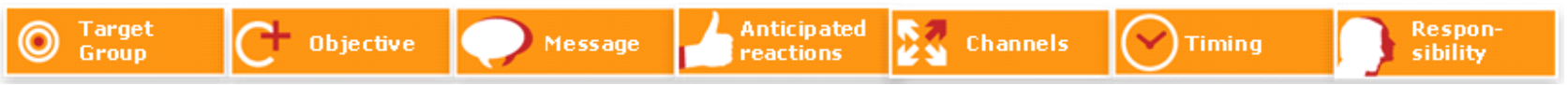

In the booklet the 7 elements are explained one by one. For example, listing the first element, the target group, is not only a question of defining whether it is a team or an individual employee. With supporting questions, as exemplified in the following, the managers are guided to a deeper reflection that eventually should have an impact on the way in which they prepare their message: 'What do they already know?', 'What do they want to know?', What do they think they know?', 'What is new to them?' and 'What might stop them from doing what you want?'.

The tool kit was first applied in the Refrigeration \& Air Conditioning (RC) division. Three of the product lines in the division each dedicated a half-day to communication in strategy workshops, where the top-level managers were invited to participate. In this session the tool kit was introduced as a tool to support the managers in the communication task they were facing after the workshop: namely, how to communicate the outcome of the workshop within the division. Rather than 
cascading the presentations communicated at the workshop, each function was asked to tailor the communication according to their target groups. This ignited interesting discussions where the managers would end up with identical overall key messages, but tailored communications. In this process, the Tool Kit also proved to be a very useful alignment tool.

Afterwards, the managers were provided with a recipe for carrying out a similar workshop with their people. In this way a train-the-trainer process was initiated. As a result, all employees ended up participating in a workshop with their immediate manager within a few months. The mission was therefore completed as:

1. The roll-out of the strategy was initiated by the immediate manager.

2. The message was tailored according to the target group.

3. The communication was based on dialogue (face-to-face or virtual).

One of the product lines in the division, 'Food Chain', took the Tool Kit one step further as the top management decided to develop their own communication strategy and asked all managers to develop similar communication strategies within their areas. "This initiative was taken in order to strengthen the cascade communication and the communication between the immediate manager and his or her direct reports", says Mette Schnefeld, HR Business Partner in Food Chain.

Looking at the Employee Perception Survey the RC division managed to raise their score on communication substantially with +6 (on a scale from 1-100) and thereby ended up with the highest score in the company. According to the divisional HR Director, Anne Vibeke Madsen, the tool kit played a vital role in creating such a good result.

The Tool Kit has since then more or less been an integrated part of strategy workshops across the divisions in Danfoss. Communication is put on the agenda as the final item where the managers are given time to align their key messages and communication plans.

A decision in the Danfoss Group Committee (The Executive Committee and the Divisional Presidents) has now been taken to make a one-day communication training for all people managers (around 2,000 managers) based on the Tool Kit. The training is currently being developed. 


\section{Author}

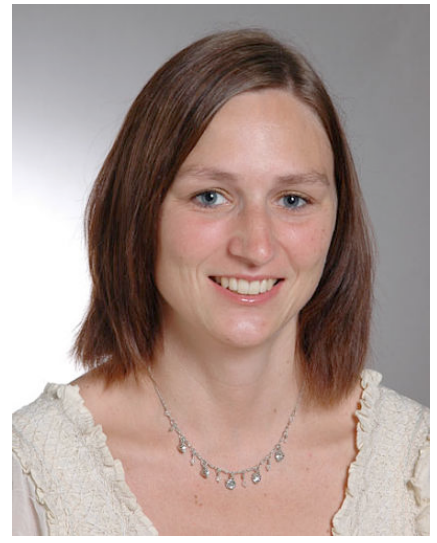

Marianne Wolff Lundholt holds a Ph.D. in narratology and linguistics. She is working as communication advisor in Danfoss. During her career she has specialized in management communication with focus on bridging $\mathrm{HR}$ and communication in order to increase the engagement within the organization. Marianne Wolff Lundholt is the author of Fortælling i virksomhedens tjeneste. Corporate Storytelling som kommunikationsredskab (Medusa 2011) and Telling without Tellers The Linguistic Manifestation of Literary Communication in Narrative Fiction (Medusa 2008).

This article was uploaded to http://www.languageatwork.eu in September of 2011 and published under a "Creative Commons license Attribution Non-commercial No derivatives (cc by-nc-sa)" for more information please go to: http://creativecommons.org/about/license/ 